\title{
Problems, Trends and Prospects of the Region's Labor Potential Development (on the Example of the Chelyabinsk Region)
}

\author{
Elena Kozhushko ${ }^{* *}$ \\ ${ }^{I}$ Federal State Budgetary Educational Institution of Higher Education «South Ural State Agrarian University», \\ Russia \\ *Email: Kolen381@yandex.ru
}

\begin{abstract}
The article deals with the problems, trends and prospects for the development of labor resources and their reproduction in the Chelyabinsk region. Each region, depending on the nature and level of the state of the economy, has its own characteristic features of the renewal of the labor force to replenish human resources. According to the results of the study, it was found that the level of development of labor resources in the Chelyabinsk region corresponds to its economic condition. In the course of further improving the processes of labor force reproduction, attention should be paid to the coordination of employment by age indicator and to eliminate the imbalance in the professional sphere through targeted training of personnel who are the most popular professions in the region's economy.
\end{abstract}

Keywords: Labor resources, Human resources, Regional economy, Reproduction of labor resources, Labor market.

\section{INTRODUCTION}

The growth of interest in the labor potential of the state as a whole and individual regions is becoming significant in the modern period of development of Russian society. This importance of labor resources is due to their importance for the stable and efficient operation of a particular organization, industry, region, or country as a whole [1].

Considering labor resources and their reproduction, it is necessary to directly correlate the development of the economy in a country or region, the need for personnel and the compliance of labor potential with the needs of the economy, its industries and enterprises [2].

Labor resources as a direct factor of production have their sources in the form of quantitative and qualitative characteristics that go through the period of formation, distribution, and redistribution and, ultimately, use in the economy of the country and region [3].

The reproduction of labor resources consists in the renewal of their quantitative and qualitative component, which includes the demographic factor, health-saving, educational, and the factor of favorable living conditions (provision of housing, comfortable conditions, including housing, environmental, and climate conditions) [4].

The reproduction process is not limited to the sphere of economy, but also affects non-economic relations in its development [5]. Socio-ethical, moral, cultural, demographic, political, and ethnic conditions that exist in society also contribute to the formation of labor potential [6]. «A national economics structure of a district is determined by the state composition of the residents, natural raw materials criteria, recreational and climatic criteria, and geopolitical location in the state» [7].

One of the quantitative factors of the reproduction process of labor potential is the demographic growth of the population [8]. But for all its positive impact on reproduction, solving only the demographic problem will not directly contribute to increasing the labor potential in Russia [9]. The current problem of reproducing the labor potential of our country is the high mortality rate of people of working age, which in the future will lead to an 
even stronger reduction in the working-age population [10].

In order to reproduce the labor force in Russia, many state measures are taken, which are expressed in the regulation of the legal framework and National projects adopted in 2018, developed in three areas: "Human capital", "Comfortable living environment" and "Economic growth". This is an important, but not the main determining factor in the reproduction of personnel in each individual region, where each factor affecting this process has its own characteristics and a certain level of state and development [11].

In connection with the above, the purpose of the research is to study the problems, trends and prospects of labor resources development in the Chelyabinsk region.

\section{RESEARCH METHODOLOGY}

In order to fulfill the research objectives, the factors affecting the process of labor reproduction were studied; the analysis of the labor market and labor reproduction in the Chelyabinsk region was carried out; the main trends, problems and prospects for the development of labor reproduction in the Chelyabinsk region were identified and the recommendations were made to improve the situation on the labor market.

The study uses statistical data analysis methods: the power-law and structural means method, the study of dynamics series, tightness of connection, and comparative analysis.

\section{THE RESULTS OF THE STUDY}

During the analysis of the state of the labor market and labor force reproduction in the Chelyabinsk region, the following was found.

In economic terms, the region is mainly represented by the metallurgical and mining industries. Recently, the agro-industrial complex has been actively developing, including animal husbandry, poultry farming, meat processing and greenhouse farming.

As of January 1, 2020, the population of the Chelyabinsk region is $3,466.960$ people (the 9 th place in the Russian Federation), the population density is 39.5 people/km2.

The urban population is $83.1 \%$. The largest cities are Chelyabinsk, Magnitogorsk, Zlatoust, Miass and Kopeysk.

Life expectancy in the Chelyabinsk region in 2018 was 71.64 years, which is slightly lower than in the Russian Federation as a whole (72.7 years) [12].

In general, over the past decade (the period 2009. 2019), the Chelyabinsk region has seen the following results of the state demographic policy: the overall mortality rate decreased from 14.4 to 13.2 per 1,000 population. But at the same time, the overall birth rate also decreased - from 13.1 to 10.8 per 1,000 population [12].

The demographic situation in the analyzed period is characterized by the dynamics of the number and natural movement of the population. So, from 2012 to 2017, the Chelyabinsk region experienced an increase in the number, and then from 2018 to 2020, a decline. At the same time, the natural population decline was $35.7 \%$ in 2019 to 2018 [12].

The state of demography of the Chelyabinsk region over a ten-year period is shown in table 1 .

Such features of the demographic situation in the Chelyabinsk region, as a decrease in the population due to natural loss and high mortality of the male population, the process of "population aging", and disproportions in the sexual structure, have a negative impact on the development of the region, constraining it [13].

One of the main socio-economic factors affecting the reproduction of labor resources is the level of monetary income, which can be judged by the average salary in the Chelyabinsk region in 2019, which amounted to 36,487. 4 rubles. At the same time, the highest average salary in the region was in professional, scientific and technical activities 53,645.7 rubles, as well as in financial and insurance 51,583. 6 rubles, the lowest in the activities of hotels and public catering 20,763.2 rubles, as well as in agriculture, hunting and forestry, fishing and fish farming 26,346.6 rubles [14].

The analysis showed that the labor market of the Chelyabinsk region has the following features.

Table 1. The state of demography of the Chelyabinsk region 2011-2020

\begin{tabular}{|c|c|c|c|c|c|c|c|c|c|c|}
\hline Demographic indicator & 2011 & 2012 & 2013 & 2014 & 2015 & 2016 & 2017 & 2018 & 2019 & 2020 \\
\hline Population, people & $\begin{array}{l}\swarrow \\
w \\
\forall \\
v \\
\sigma \\
w \\
\square\end{array}$ & 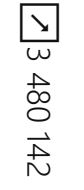 & $\begin{array}{l}\nu \\
w \\
\infty \\
\infty \\
\sim \\
\sim \\
N\end{array}$ & $\begin{array}{l} \\
w \\
\Delta \\
0 \\
0 \\
0 \\
w\end{array}$ & $\begin{array}{l} \\
w \\
\vec{v} \\
\underset{D}{N} \\
\stackrel{D}{*}\end{array}$ & $\begin{array}{l}y \\
\\
y \\
\varnothing \\
0 \\
\stackrel{v}{ } \\
\vec{\sigma}\end{array}$ & $\begin{array}{l}\nu \\
w \\
\cup \\
\sim \\
w \\
w \\
w\end{array}$ & \begin{tabular}{l}
\multicolumn{1}{l}{} \\
$w$ \\
$\vec{b}$ \\
$w$ \\
$\stackrel{\omega}{\sigma}$
\end{tabular} & $\begin{array}{l} \\
w \\
\pm \\
v \\
v \\
w\end{array}$ & 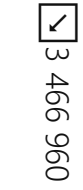 \\
\hline
\end{tabular}


According to the express information of the Employment Service for the Chelyabinsk region, as of October 1, 2020, the registered unemployment rate in the region was $4.92 \%$ of the labor force, and the tension in the labor market was 2.93 people/vacancy. compared to September 2019, these figures were $1.09 \%$ and 0.89 people/vacancy [14].

Registered in the employment centers of the population consists of: unemployed citizens -98943 (23469 in the same period of 2019) people, unemployed -92285 (20378 in the same period of 2019) people. The number of available vacancies in the employment centers of the region, declared by the organizations of the region of the need for employees - 33551 (26029 for the same period of 2019) [14].

As of 2020, the Chelyabinsk region's economy's human resource needs were formed in the amount of $1,759,405$ people, with the overall level of satisfaction of the region's human resources needs by $97 \%$ and an imbalance of 52,811 people, which the region does not have enough to cover labor needs [14].

In 2019, the overall staffing demand for the region was mainly due to demand generated mainly by manufacturing, trade and public catering, construction, education, transportation and storage, agriculture, and healthcare. The remaining 11 types of economic activity accounted for $23.42 \%$ of the region's personnel needs, and in such types of economic activities as education, culture, sports, leisure and entertainment, as well as in professional, scientific and technical activities, one hundred percent satisfaction of personnel needs. There is a shortage of personnel in trade and public catering, which amounted to 16,990 people.

The Chelyabinsk region is characterized by a high level of labor force quality, as the share of employees with higher education is $34.98 \%$ of the average annual number of employees; secondary vocational education $30.08 \%$; vocational education $-20.38 \%$, and $14.56 \%-$ without vocational education [14].

Over the ten-year period analyzed, the structure of the employed population in the Chelyabinsk region has shifted the level of quality of the labor force by age parameters. Thus, in the employed population, the share of people in the age category from 50 to 59 years, as well as from 60 years and above, has increased, while the category of young people aged 20 to 29 years is decreasing by this indicator.

According to G. Cherednichenko: "Higher unemployment rates for all groups of graduates are observed in those age groups that mainly account for the completion of training in a particular category of educational organizations." In the same place: "the most urgent demand of practice for the education system today is to smooth out the disproportions between the structure of training in the education system and the structure of demand in the labor market. Modernization and reform of the education system are the important factors in reducing the existing tension here" [15].

The large share of the unemployed $(32.2 \%)$ aged 30 39 years is also alarming. They make up the most active and professionally developed category of labor resources in the region. The loss of skills and personal destruction that inevitably accompany the inactivity of the full forces of this age group of the unemployed leads to the destruction and reduction of the quality of the labor force [16].

\section{CONCLUSIONS}

Thus, the demographic component of the region's labor resources indicates a decrease in the number of the region's population due to natural decline. The analysis of the qualitative component of the labor force showed that it is at a sufficient level, since the main share in the structure of labor force education is made up of employees with higher and secondary vocational education. In the Chelyabinsk region, there is a deterioration in indicators that reflect the level of quality of the labor force by age parameters. In addition, the migration processes taking place in the interregional and international direction have a balancing character with respect to the entry and exit of the working-age population from the region.

The forecast of the total personnel demand of the Chelyabinsk region showed that if the current trends in the development of the region's economy and its industries continue, there will be a small increase in personnel demand in the medium and long term. The largest human resource demand in the Chelyabinsk region is projected in manufacturing industries, which form the basis of the industrial region's economy. This need tends to increase. The need for personnel in agriculture and fish farming will also increase, construction will remain at a constant level, and transportation and storage will decrease.

The growth of labor productivity in a developing economy is due to digitalization and automation of all production processes, which explains the low growth in the need for personnel in the region [14].

In order to detail the efforts aimed at improving the quality of the workforce, using data from the analysis and forecast of the Chelyabinsk region's staffing needs and its imbalance, we suggest planning the allocation of budget places for appropriate education on a targeted basis. The projected total increase in the workforce demand in the manufacturing industry for the long-term period from 2020 to 2036 will be 43,935 people. On average, the need for personnel will amount to 2,746 people per year, with the average cost of training (according to Rosstat) at 68.9 thousand rubles for this period. Based on this, the annual cost of eliminating personnel requirements may amount 
to 189199.4 thousand rubles per year. The number of budget places in higher education institutions in the region for technical specialties is 1000 units, which are mainly provided by the leading University of the Chelyabinsk region, South Ural State University. 2770 places for technical specialties are provided by secondary vocational educational institutions of the Chelyabinsk region, which suggest that they can completely cover the region's need for personnel. These places can be targeted by connecting employers to solve the problem, in particular, by providing them with applications for training specialists with certain competencies and providing places of practice in the workplace.

\section{REFERENCES}

[1] E.A. Kozhushko, Formation of personnel regional policy in the agricultural sector in the conditions of modern economic development of the Chelyabinsk region, Competitiveness in the global world: economics, science, technology 8-3(55) (2017) 5358 (In Russ.).

[2] E.A. Kozhushko, Human resources potential of the Chelyabinsk region in the transition to an innovative regional economy, Bulletin of the Chelyabinsk State University 10(406) (2017) 54-62 (In Russ.).

[3] E.A. Kozhushko, Human capital in the transition to an innovative economy, Economics of education 6(103) (2017) 5-12 (In Russ.).

[4] M. Beerkens, E. Mägi, L. Lill, University Studies as a Side Job: Causes and Consequences of Massive Student Employment in Estonia, Higher Education Vol. 61 Iss. 6 (2011) 679-692.

[5] P. Robert, E. Saar, Learning and Working: The Impact of the 'Double Status Position' on the Labour Market Entry Process of Graduates in CEE Countries. European Sociological Review Vol. 28 Iss. 6 (2012) 742-754.

[6] Scott E. Masden, Old School Ties: Financial Coordination and the Governance of Higher Education//Journal of Economic Behavior and Organization 28:1 (1995) 23-48.

[7] V.R. Markaryan, K.Y. Litvina, E.Y. Kamchatova, V.A. Chernova, E.A. Kozhushko, Globalization and Problems of Modern Regional Economy, Systematic Reviews in Pharmacy 11(4) (2020) 348353. DOI: https://doi.org/10.31838/srp.2020.4.51

[8] E.A. Kozhushko, V.I. Kozhushko, Formation of personnel potential in the conditions of digitalization of the agro-industrial complex, Topical issues of humanities, economics and natural sciences: theory and practice : materials of the national scientific conference of the Institute of agricultural engineering, Chelyabinsk, 2020, pp. 173-182 (In Russ.).

[9] F. Novokmet, T. Piketty, G. Zucman, From Soviets to oligarchs: Inequality and property in Russia 1905-2016, The Journal of Economic Inequality 16 2 (2018) 189-223.

[10] M. Karadja, J. Mollerstrom, D. Seim, Richer (and holier) than thou? The effect of relative income improvements on demand for redistribution, Review of Economics and Statistics 992 (2017) 201-212.

[11] E.A. Kozhushko, V.I. Kozhushko, Actual tasks of forming the main directions of regional policy for the reproduction of human resources in agriculture of the Chelyabinsk region, New challenges of higher education in the field of social sciences: subject, methods and technologies: proceedings of the allRussian scientific and methodological conference, November 27-28, 2019, Chelyabinsk, 2019, pp. 227-233 (In Russ.).

[12] Federal state statistics service, 2020, Retrieved from: https://rosstat.gov.ru/ (In Russ.).

[13] E.V. Sleptsova, A.A. Uzunyan, Problems of labor potential reproduction in the Russian Federation, Economics and business: theory and practice 12 (201) 134-136 (In Russ.).

[14] Employment and unemployment in the Chelyabinsk region, Official website of the Main Department for labor and employment of the Chelyabinsk region, 2020. Retrieved from: http://szn74.ru/htmlpages/Show/Rynoktruda/Zanya tostibezraboticavCHelyabi (In Russ.)

[15] G. Cherednichenko, Employment and Labor Market Outcomes of College and Vocational School Graduates, Voprosy obrazovaniya/Educational Studies Moscow 1 (2020) 256-282.

[16] E.A. Nezhivenko, S.A. Golovikhin, G.V. Nezhivenko, The quality of the labor force of an industrial region as a factor in the formation of its competitiveness potential, Fundamental research, 8 (2019) 65-69 (In Russ.). 